\title{
A Novel Work on the Thermal Behaviour of Natural Fiber Reinforced Epoxy Composites
}

\author{
C. M. Meenakshi, Sucharitha S, Ravi D
}

\begin{abstract}
The need for bio degradable material in all the fields including automobile and mechanical field is growing due to the awareness and polution and enviromenat safety norms. To satisfy this need needs, alternative natural product with similar kind of properties has to be identify. Where these natural products attribute can be enhanced using some processing techniques and by adding suitable chemicals. Composite materials are the one which is ruling our world and the need for them is marginally high and we need to find new enhanced matrices which have much more good qualities than the old one and find the alternate for them in their existence.

The hybrid composite manufacturing has been wide range of investigations. The composites have superior properties like light weight, low density, stiffness, and better mechanical properties. The present work aims on mechanical and thermal behaviours of GKG, GAG, and KGA fibre reinforced epoxy composites. Hand layup method used for fabricate hybrid composite laminates. The thermogravimetric analysis, heat distortion temperature test are carried out to find its thermal stability. For testing and analysis, the specimens are cut as per ASTM standards.
\end{abstract}

Keyword : Composite materials, Hypothermal Exposure

\section{INTRODUCTION}

Composites become the most sorted material due to its leight weight and strength also providing design flexibility because many of them can be molded into complex shapes. Natural fibre reinforced composites found applications in both engineering and service sectors. Polymer composite materials frequently have mechanical and physical properties that improve them appropriate for a wide scope of uses than the individual composite segments[1],[3],[5]. The utilization of normal fiber improvement of polymeric materials that are created from supportable and naturally composites ordinarily have a fiber or molecule stage that is stiffer and more grounded than the persistent lattice stage and serve "composites are multifunctional material frameworks that give qualities not reachable from any discrete material. The NFC separated flax FIBERs have been found to have quality $20 \%$ higher than those removed precisely. The Fabrication Reinforced Composites (FRC) is expanding quickly in the car, aviation and wind vitality parts in view of their high explicit quality and modulus. This task work went for the uses of Natural plant strands, for example, flax, sisal and

Revised Manuscript Received on August 22, 2019.

CM Meenakshi, Department of Mechanical Engineering, Bharath Institute of Higher Education and Research, Chennai, Tamilnadu, India. Email: cmmeenakshidhanush@gmail.com

Sucharitha S, Department of Mechanical Engineering, Bharath Institute of Higher Education and Research, Chennai, Tamilnadu, India.

Email: saisuchi2002@gmail.com

Ravi D, Department of Mechanical Engineering, Bharath Institute of Higher Education and Research, Chennai, Tamilnadu, India.

Email: ravivsravi.aero@gmail.com delivering a characteristic based material composite overlay produced using sustainable agrarian and ranger service feedstock. The characteristic fiber utilized will be synthetically treated to improves its exhibition and the overlay will be set up with this treated strands. At that point it will be exposed to mechanical portrayal and broke down[2],[4],[6].

\section{RELATED WORKS}

In 2013, N. Abilash, M. Sivapragash considered on advancing the delamination disappointment in bamboo fiber fortified polyester composite. They examined on bamboo fiber strengthened with polyester in pressure shaping strategy. They directed dim worth test on the composite. They presumed that by diminishing the feed rate and drill distance across delamination impact can be limited that prompts better quality openings.

In 2013, M. Ramesh, K. Palanikumar, K. Hemachandra Reddy contemplated on the near assessment on properties of cross breed glass fiber-sisal/jute fortified epoxy composites. They directed pliable and flexural test on the composite. They finished up that performance of normal fiber composites is lower than that of GFRP. Sisal-GFRP composite perform better in ductile stacking and jute-GFRP composites better in flexural stacking.

In 2014, A. BelaadIa, A. Bezazi, M. Maache, F. Scarpa examined on weakness in sisal fiber fortified polyester composites: hysteresis and vitality scattering. The investigation was about sisal fiber strengthened polyester composite[7],[9],[11]. The tests led on the fiber are pliable test, weariness test, static test. They presumed that the examination of sisal polyester bio composites exposed to 3point bowing under static stacking demonstrates that hysteresis circle and disseminated vitality per unit volume as an element of cycle number is profoundly reliant on stacking level on the example.

\section{SAMPLES FOR MECHANICAL CHARACTERIZATION}

Composite laminates prepared are cut into smaller samples of ASTM standards, for various test procedure and the sized specimens are shown in the forthcoming figures[19],[21],[22].

\section{A. Heat Deflection Temperature}

The warmth mutilation (or warmth diversion) temperature (HDT) is a significant property of polymers. It gives a sign at what temperature materials begin to "relax" when presented to a fixed burden at raised temperatures. The HDT is characterized by ASTM D 648 as the temperature at which an example bar of standard 
measurements (120x $10 \times 4 \mathrm{~mm})$ avoids by $0.25 \mathrm{~mm}(0.01 \mathrm{in})$ less than a focused standard flexural heap of $9 \mathrm{MPa}$. The example is warmed in a submersion shower at a pace of $20 \mathrm{C} / \mathrm{min}$.

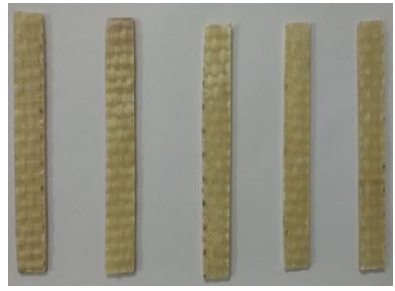

Figure 1- Tensile test Specimen

\section{B. Thermogravimetric Analysis}

Thermogravimetric examination (TGA) is a technique used to locate the material's warm dependability aby checking the weight change that happens as an example is warmed at a consistent rate[8],[10],[12]. The test is generally completed in air or in a latent environment, for example, nitrogen or argon, and the weight is recorded as an element of expanding temperature. There are a few reports on the interfacial portrayal of characteristic fiber fortified polymer composites utilizing thermo gravimetric investigation (TGA).

\section{RESULT AND DISCUSSION}

\section{A. Heat Deflection Test}

\begin{tabular}{|c|c|c|c|c|c|c|}
\hline \multirow{2}{*}{ Sample } & \multicolumn{7}{|c|}{ Heat deffection temperature (C) } \\
\cline { 2 - 7 } & 1 & 2 & 3 & 4 & 5 & Average \\
\hline GKG & 70 & 74 & 73 & 74 & 75 & 73.2 \\
\hline GAG & 67 & 68 & 66 & 67 & 65 & 66.6 \\
\hline KGA & 75 & 73 & 74 & 74 & 75 & 74.2 \\
\hline
\end{tabular}

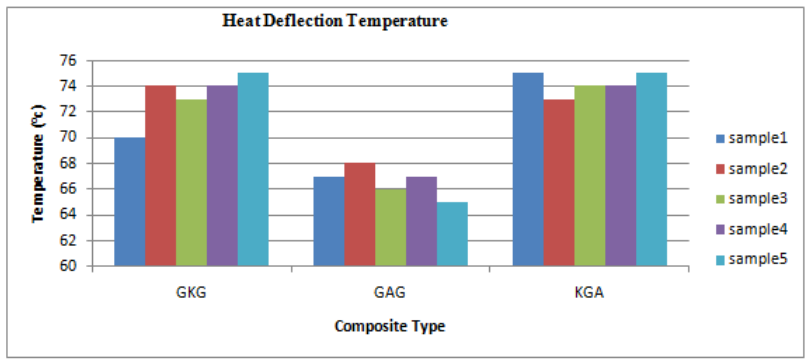

\section{B. Thermogravimetric Analysis}

From the graph we understood that the GKG sudden degradation starting in 319.1 Celsius. The degradation temperature goes on till 690.5 Celsius[13],[15],[17]. The results are shown in graph in figure 4.

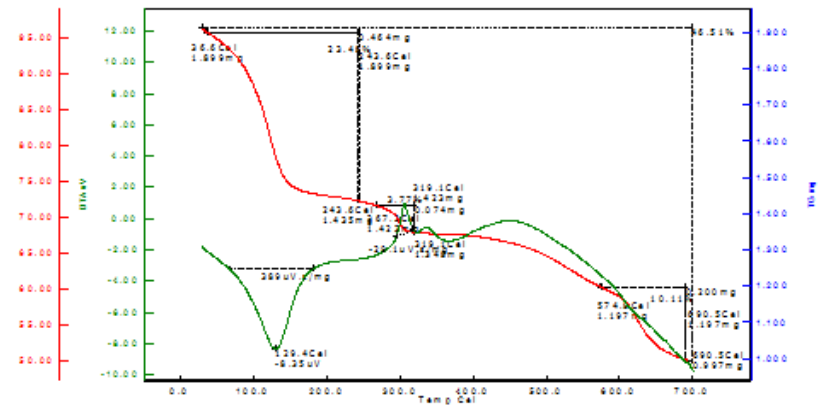

From the graph we understood that the GAG sudden degradation starting in 427 Celsius. The degradation temperature goes on till 808 Celsius. The results are shown in graph in figure 5

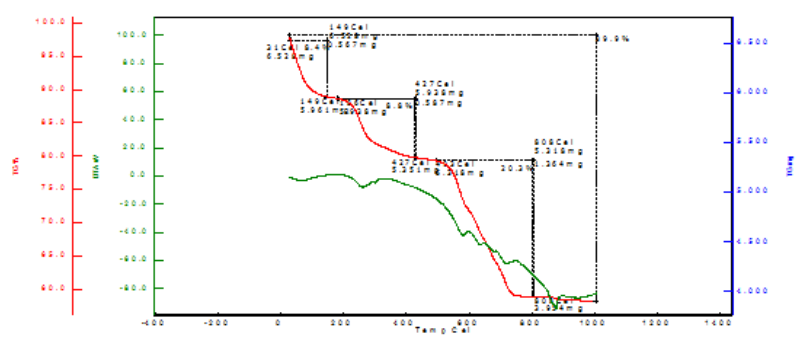

From the graph we understood that the KGA sudden degradation starting in 509.7 Celsius. The degradation temperature goes on till 690.5 Celsius. The results are shown in graph in figure 6.

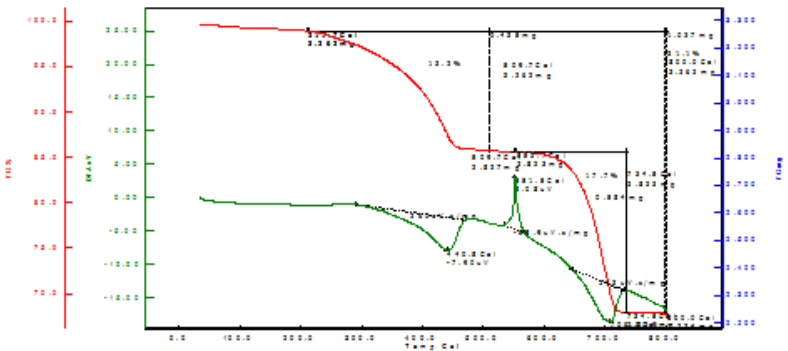

\begin{tabular}{|c|c|c|c|c|}
\hline \multirow{2}{*}{ Composite type } & \multicolumn{4}{|c|}{ Tensile Strength N/mm ${ }^{2}$} \\
\cline { 2 - 5 } & Sample 1 & Sample 2 & Sample 3 & Average \\
\hline GKG & 68.97 & 70.37 & 63.62 & 67.65 \\
\hline GAG & 69.86 & 63.95 & 58.92 & 64.24 \\
\hline KGA & 29.88 & 32.08 & 28.89 & 30.28 \\
\hline
\end{tabular}

\section{Comparison of Thermogravimetric Result}

The thermogravimetric analysis result shows that the hybrid composite is showing equally good performance to glass fiber reinforced composite and natural fiber reinforced composite is also showing positive result[14],[16],[18]. From the table we understood that the KGA degradation temperature is higher when compared to GKG and GAG. The less degradation temperature obtained by GKG when compare to GAG and KGA. The results are shown in below table. 


\begin{tabular}{|c|c|c|}
\hline \multirow{2}{*}{ Composite type } & \multicolumn{2}{|c|}{ Thermograximetric Analysis Temperature (Celsius) } \\
\cline { 2 - 3 } & Initial Degradation Temperature & $\begin{array}{c}\text { Complete Degradation } \\
\text { Temperature }\end{array}$ \\
\hline GKG & 319.1 & 690.5 \\
\hline GAG & 427 & 808 \\
\hline KGA & 509.7 & 800 \\
\hline
\end{tabular}

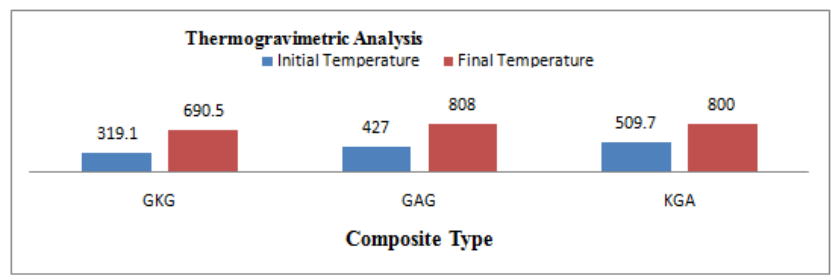

\section{CONCLUSION}

Three types of composite laminates are fabricated using hand layup method with Glass, Kenaf and Aloe vera fibers in Epoxy Resins and their mechanical and thermal properties are studied. From the results the following conclusions are made. - From heat deflection temperature test, it is understood that KGA and GKG are having the high temperature withstanding capacity.

- From thermogravimetric analysis, KGA had maximum degradation temperature.

The overall results shows, the hybridization of natural fiber along with the glass fiber has good impact on the thermal capacity of the composites. Also we found that, if the proportion of natural fibre increased then the thermal ability will be increased.

\section{REFERENCES}

1. Tatikonda, N.C. \& Naveenchandran, P. 2019, "The behaviour of a compression ignition engine under the influence of diesel and microalgae biodiesel blends", International Journal of Mechanical and Production Engineering Research and Development, vol. 9, no. 4, pp. 447-456.

2. Tatikonda, N.C. \& Naveenchandran, P. 2019, "An experimental assessment on the impact of injection pressure on the characteristics of a diesel engine powered with the blend of diesel and microalgae biodiesel", International Journal of Engineering and Advanced Technology, vol. 8, no. 6, pp. 3284-3291.

3. Karthikeyan, S., Raman Balasubramanian, S.R., Ramesh, B., Raghul, S. \& Sathish Kumar, S. 2019, "The automatic solar tracker chronicles", International Journal of Recent Technology and Engineering, vol. 8, no. 1, pp. 312-315.

4. Hema, R., Sundararajan, M. \& Balaji, S. 2019, "Smartphone control robot with automatic firing gun", International Journal of Innovative Technology and Exploring Engineering, vol. 8, no. 9 Special Issue 3 , pp. 625-627.

5. Saritha, B., Chockalingam, M.P. \& Aswathy, M. 2019, "Degradation of anionic dye using $\mathrm{Fe} / \mathrm{Tio} 2$ composite by photocatalysis", International Journal of Innovative Technology and Exploring Engineering, vol. 8, no. 9 Special Issue 3, pp. 788-791.

6. Saritha, B., Maria Subashini, L. \& Aswathy, M. 2019, "Utilization of spent coffee grounds for compost production", International Journal of Innovative Technology and Exploring Engineering, vol. 8, no. 9 Special Issue 3, pp. 908-910.

7. Fernando, J.K., Meikandaan, T.P. \& Hemapriya, M. 2019, "Better utilisation of bottom ash in coal fired thermal power station", International Journal of Innovative Technology and Exploring Engineering, vol. 8, no. 9 Special Issue 3, pp. 898-900.

8. Kumar, K.S., Kiruthiga, K. \& Thendral, S. 2019, "Experimental analysis on fractional substitution of bond by utilizing rice husk cinder", International Journal of Innovative Technology and Exploring Engineering, vol. 8, no. 9 Special Issue 3, pp. 1163-1165.
9. Vignesh, P., Madan, P., Mohankumar, D. \& Naveenchandran, P. 2019 "Optimization of four stroke c.i. engine performance by using statistical techniques (mathematical method)", International Journal of Recent Technology and Engineering, vol. 8, no. 2, pp. 1685-1691.

10. Bharanidharan, S., Sathiyamurthy, K. \& Sheeba, B. 2019, "Using co-precipitation method determining synthesis and characterization of fe doped zinc oxide nanoparticles", International Journal of Innovative Technology and Exploring Engineering, vol. 8, no. 9 Special Issue 3, pp. 705-707

11. Jeevanandan, D. \& Vino, J.A. 2019, "Heat recovery from boiler blowdown water by using heat exchanger in thermal power plant", International Journal of Mechanical and Production Engineering Research and Development, vol. 9, no. 3, pp. 219-222.

12. Rakesh, N.L., Balambica, V. \& Kannan, S. 2019, "Biogas extraction from waste orange peel by digestion process", International Journal of Mechanical and Production Engineering Research and Development, vol. 9, no. 3, pp. 323-330.

13. Meenakshi, C.M. \& Krishnamoorthy, A. 2019, "The mechanical characterization of mono and hybrid fiber reinforced composites using experimental and finite element analysis methods", International Journal of Mechanical and Production Engineering Research and Development, vol. 9, no. 3, pp. 189-196.

14. Mohankumar, D., Prem Jayakumar, M., Sabarsish, R. \& Naveen Chandran, P. 2019, "Modeling and experimental investigation on centrifugal blower by computational fluid dynamics", International Journal of Mechanical and Production Engineering Research and Development, vol. 9, no. 3, pp. 331-340.

15. Balambica, V., Deepak, V. \& Kumar, S. 2019, "Design and efficiency of an asymmetric gear", International Journal of Mechanical and Production Engineering Research and Development, vol. 9, no. 3, pp. 223-230.

16. Manavalan, S., Balakrishnan, G. \& Ramasubramaniam, S. 2019, "An effect of cobalt oxide nano additive with biodiesel blends using cidi diesel engine", International Journal of Mechanical and Production Engineering Research and Development, vol. 9, no. 3, pp. 211-218.

17. Golden Renjith Nimal, R.J., Sivakumar, M. \& Esakkimuthu, G. 2019, "An investigation on mechanical properties and microstructure of mg/al alloys using zn interlayer during diffusion bonding", International Journal of Mechanical and Production Engineering Research and Development, vol. 9, no. 3, pp. 125-130.

18. Hariharan, R., Raja, R. \& Vasu, S. 2019, "Mechanical and tribological behaviour of thin tan coating produced on AISI 1018 substrate by DC magnetron sputtering", International Journal of Recent Technology and Engineering, vol. 7, no. 6, pp. 591-598

19. Manavalan, S., Rai, R., Kumar, R.R., Chaudhary, R.K. \& Chaudhary, S.K. 2019, "Impact of modified piston - A review", Internationa Journal of Recent Technology and Engineering, vol. 8, no. 6, pp. 616-620.

20. Manavalan, S., Gopi, A., Arivarasu, J., Abishek Ahi, A. \& Chandru, S. 2019, "Review on ceramic disc brake system", International Journal of Recent Technology and Engineering, vol. 7, no. 6, pp. 612-615.

21. Sabarish, R. \& Jeya Kumar, M.P. 2019, "The design and analysis of piston - Steady state thermal analysis using "ansys"", International Journal of Mechanical and Production Engineering Research and Development, vol. 9, no. 3, pp. 197-204.

22. Ravi, D. 2019, "CFD simulation of solar loading in car", International Journal of Mechanical and Production Engineering Research and Development, vol. 9, no. 3, pp. 231-236.

\section{AUTHORS PROFILE}

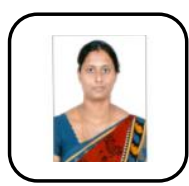

C.M. Meenakshi Assistant Professor, Department of Mechanical Engineering, Bharath Institute of Higher Education and Research, Chennai, India.

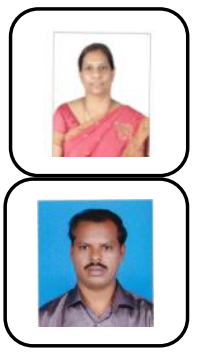

Sucharitha S Assistant Professor, Department of Mechanical Engineering, Bharath Institute of Higher Education and Research, Chennai, India.

Ravi D Assistant Professor, Department of Mechanica Engineering, Bharath Institute of Higher Education and Research, Chennai, India. 